\title{
Observations of the Antarctic ice sheet with the Seasat scatterometer: relation to katabatic-wind intensity and direction
}

\author{
M. LEDRoit, F. REMY AND J. -F. MinSTER \\ UMR 39/GRGS, 18 av E. Belin, 31055 Toulouse, France
}

\begin{abstract}
The Seasat A satellite scatterometer radar, initially designed to measure ocean-wind intensity and direction, also provided observations on the Antarctic ice sheet. The signal of the back-scatter coefficient decreases strongly from 10 to $-20 \mathrm{~dB}$ when the incidence angle of the observations increases from $0^{8}$ to $65^{\circ}$. An additional $5 \mathrm{~dB}$ signal is found, which is correlated with the direction and intensity of katabatic winds, independent of the incidence angle and polarization of the signal. By using simplified models of the volume-scattering within the snowpack (which is mostly sensitive to snow grain-size) and surface-scattering from the airsnow interface (which depends on roughness), it is evident that the signal of the scatterometer could result from the effects of snow dunes at low incidence angle, and of micro-roughness and volume back-scatter at incidence angles greater than $25^{\circ}$. The instrument therefore provides a means of measuring the direction and intensity of katabatic winds.
\end{abstract}

\section{INTRODUCTION}

Passive or active observations of ice masses in the microwave domain may provide important parameters, if the dielectric behaviour of the snow is well known, which is not the case. For example, satellite-radar altimeters allow the mapping of ice-surface topography (Zwally and others, 1983; Remy and others, 1989) if the signal is not affected significantly by volume-scattering within the snowpack.

Passive microwave radiometry, which is sensitive to the grain-size profile in the upper few meters below the snow surface (Zwally, 1977), may provide a measurement of accumulation rate (Rotman and others, 1982). However, Remy and Minster (1991) suggested that the polarization of microwave emission is affected by surface micro-roughness of the ice sheets. Matzler (1987) also suggested that internal layering plays an important role in the radiometric signal.

The behaviour of microwaves in the snowpack is not understood well because of the complexity of this natural medium (Rott, 1989). The signal can be affected by surface, sub-surface and volume back-scatter, or by surface roughness on various scales. Parameters such as temperature, grain-size, statistics of the surface roughness and snow layering must be considered. Theoretical studies are, therefore, complex and inconclusive. Empirical studies of altimetric return power or radiometer emissivity are also limited. Remy and others (1990) showed that the intensity of the Seasat altimeter return power over Antarctica varies in strong correlation with the intensity of model katabatic winds. This can be explained by surface-scattering, which is related to surface micro-roughness (Fung and Eom, 1982) created by the surface wind or by volume-scattering, which is proportional to the snow grain-size, also affected potentially by wind speed.

The nature of microwave back-scatter coefficients on snow is examined here empirically using scatterometer data. (The back-scatter coefficient is the ratio of the return power over the incidence power, generally expressed in decibels.) The advantage of the scatterometer radar instrument is that it provides observations for several incidence and azimuth angles (see Fig. 1 for definition), and for both horizontal and vertical polarizations of the signal. For the Seasat scatterometer, each satellite path provides 15 values at two different incidence angles for both polarizations. Contrary to other instruments (altimeter or radiometer) which provide single observations, scatterometer readings contain about 60 different observations per satellite path (i.e. 15 observations by each of two antennas at two polarizations). This large data set may better describe the different scattering processes. Further theoretical studies suggest that at small incidence angles, the back-scatter coefficient will be sensitive to surface-scattering, whereas at greater incidence angles, volume-scattering will be dominant (Fung and Eom, 1982). Swift and others (1985) reached the same conclusion from studies of airborne microwave measurements above the Greenland ice sheet. Yet, to our knowledge, no previous study of the Seasat scatterometer data above continental ice sheets has been published.

The physical principles of the Seasat scatterometer are introduced in the first section of this paper. The variations of the back-scatter coefficient as a function of different parameters are then analyzed empirically using data from 


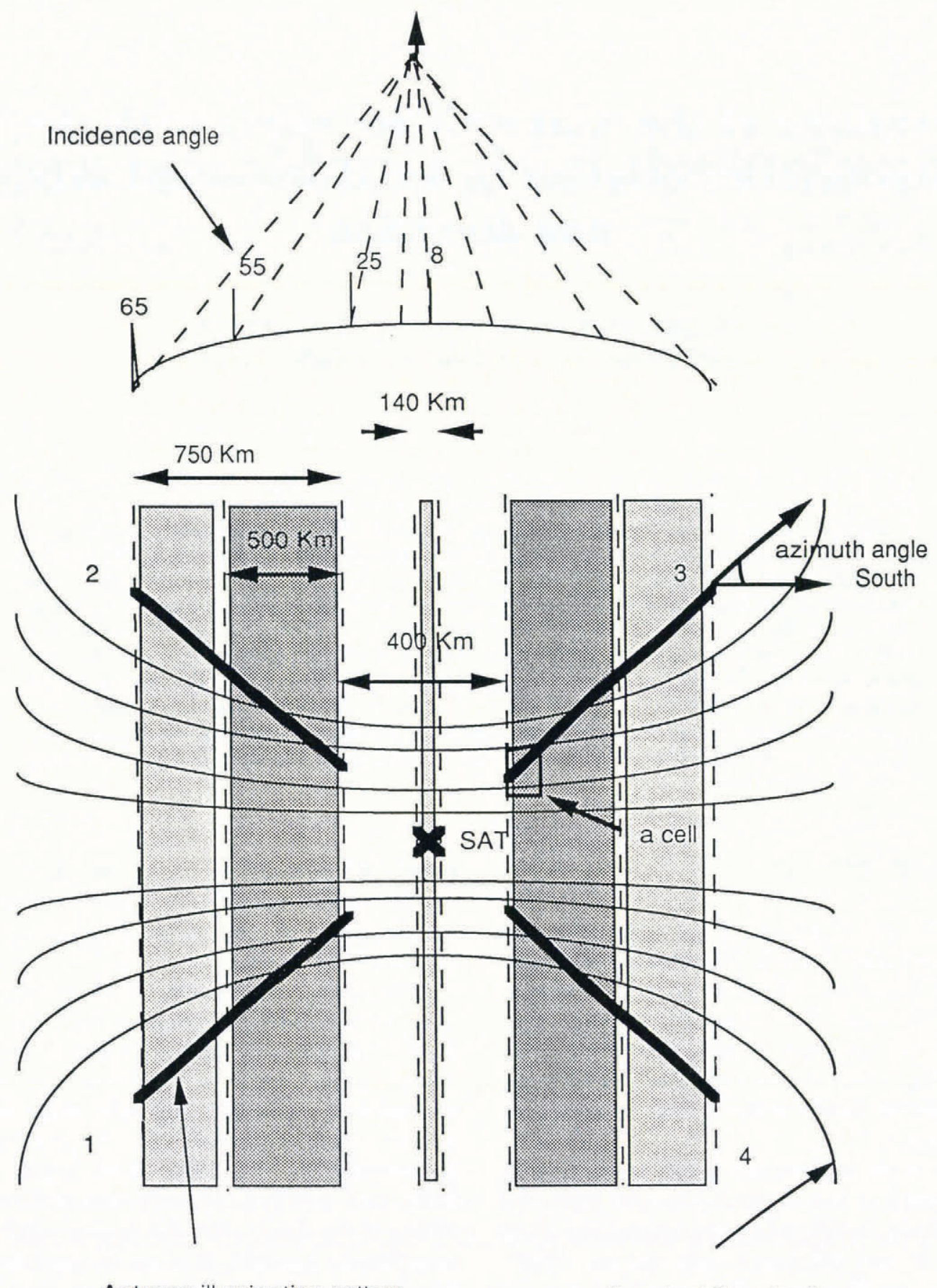

Antenna illumination pattern

Constant Doppler lines

Fig. 1. Geometry of the observations by the Seasat A scatterometer (adapted from Johnson and others, 1980). The lines in the figure represent the lines of constant Doppler effect on the echo, which is used to separate the data into cells.

various areas of the Antarctic ice sheet. The direction and intensity of the surface winds are calculated in the third section. The results of simple theoretical models of surface- and volume-scattering are compared with the observations in the last section.

\section{THE SEASAT-A SATELLITE SCATTEROMETER}

The SASS (Seasat-A satellite scatterometer) was designed to measure ocean-surface wind speed and direction. It has been described in detail by Johnson and others (1980) and Bracalente and others (1980). It operates at a microwave frequency of $14.6 \mathrm{GHz}$ with four beam antennae. Two antennae view each side of the satellite, each one at an angle of $45^{\circ}$ relative to the satellite track (forward and backward) (Fig. 1). Each of these antennae is composed of 15 "cells" (corresponding to different angles varying from 0 to $64^{\circ}$ ) giving measurements of the back-scatter coefficient. Three cells operate at small incidence angles $\left(0-8^{\circ}\right)$ and 12 at large incidence angles $\left(25-64^{\circ}\right)$. One cell is represented by an incidence angle varying by about $3^{\circ}$, leading to a resolution of $50 \mathrm{~km}$ in the antenna beam direction and $16 \mathrm{~km}$ perpendicular to it. Measurements are taken every $1.89 \mathrm{~s}$, the antenna 
switching cycle being completed in $7.56 \mathrm{~s}$. The backscatter coefficient in each cell is derived by averaging 15 individual measurements.

The use of independent measurements from two antennae with orthogonal azimuthal viewing angles for each cell was required to deduce both wind speed and direction above the ocean. Indeed, for a given incidence angle, the radar back-scatter is observed to vary with azimuth angle following a bi-sinusoidal curve (Fig. 2). The same figure also indicates variations of the backscatter coefficient with incidence. In the following study, our results are compared with those shown in Figure 2. In the case of the ocean, models including a statistical description of sea-surface height and slope distributions are used to explain the observed signal. An empirical approach is used here in the case of the ice sheets.

\section{METHODOLOGY}

The surface roughness of the ocean and ice sheets have very different statistical characteristics. For the ocean, the

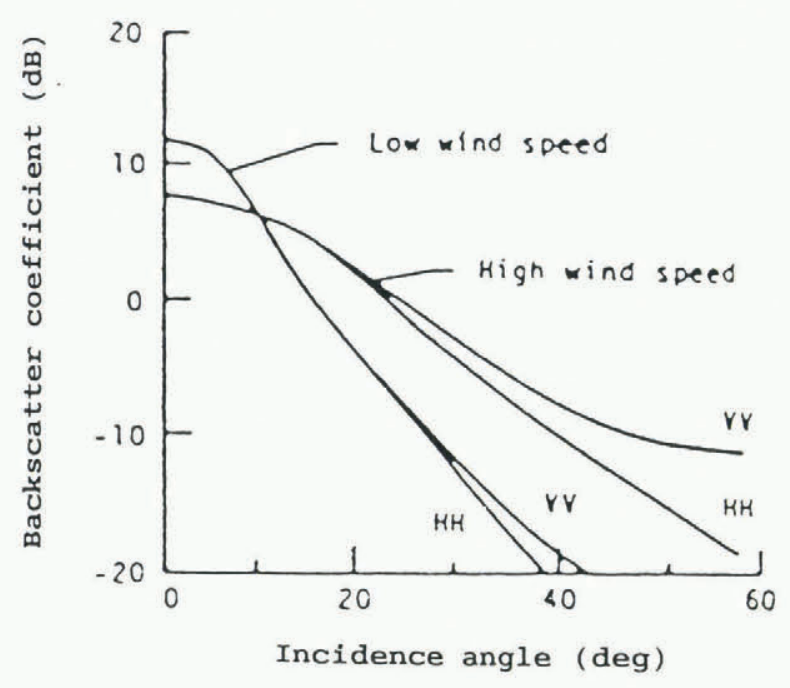

吕

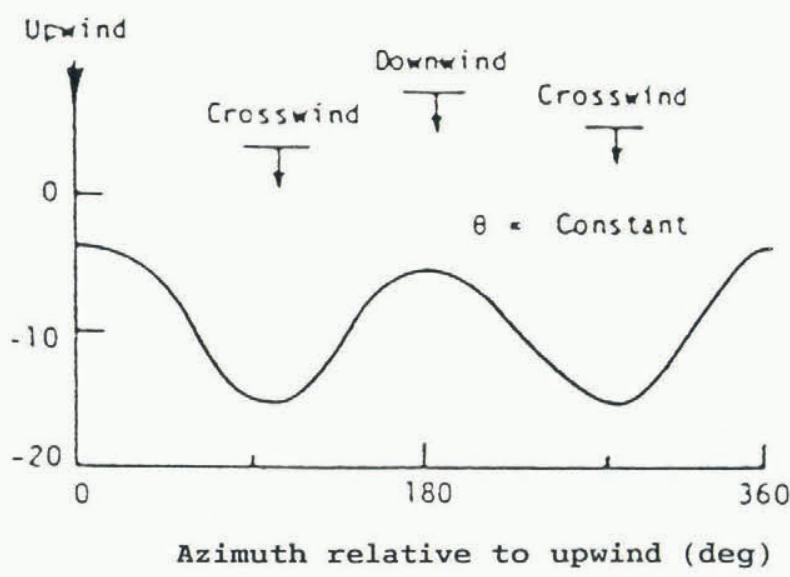

Fig. 2. Typical variations of the back-scatter coefficient $\sigma_{0}$ above the ocean as a function of incidence angle $\theta$, of polarization ( VV or $H H$ ), of wind speed and azimuth relative to the wind (adapted from Stewart, 1985). This figure will be used as a reference to ice-sheet data. temporal evolution of surface sea state is very rapid and the spatial signal has a large wavelength (the synoptic scale of the atmosphere). This is because the ocean and surface gravity waves respond quickly to atmospheric winds. For the Antarctic ice sheet, the back-scatter is expected to be "quasi-permanent", as all parameters (temperature, grain-size, surface roughness) may remain constant on the decadal time-scale (personal communication from D. H. Bromwich). In addition, even though the intensity of the wind varies strongly with time, the geography of its pattern is stationary. Indeed, the prevailing winds are katabatic, their flowlines being mostly controlled by the ice-sheet topography and by the Earth's rotation (Fig. 3). The Seasat altimeter backscatter coefficient averaged over time varies on the distance scale of $100 \mathrm{~km}$ (Fig. 4). This provides an a priori estimate of the length scale of variations for the scatterometer signal, at nadir, because it operates at the same frequency as the altimeter.

Four regions characterized by the following criteria are analyzed: a sufficiently large surface to contain data at many azimuth and incidence angles and a sufficiently small surface for the "forcing" parameters to be spatially homogeneous (in order to help separate their effects). The latter include two effects: strength of the wind for the potential effects on surface echo and grain-size for the effects on volume echo. The former depends on the lateral convergence and divergence of the flow, and on the terrain slope (Parish and Bromwich, 1991). It is, therefore, to a first order, related inversely to the altitude and to the distance between katabatic-wind flowlines in Figure 3, and may be deduced from Parish and Bromwich (1991). The latter effect is affected strongly by temperature (or equivalently, by altitude to a first order), as low temperatures induce large grain-sizes.

This results in the regions shown in Figure 3: region A is characterized by a light wind and high altitude $(2900 \mathrm{~m})$, region B by a very strong wind and relatively low altitude $(1800 \mathrm{~m})$, region $\mathrm{C}$ by a strong wind and high altitude $(2800 \mathrm{~m})$ and region $\mathrm{D}$ by a strong wind and low altitude $(2000 \mathrm{~m})$.

In this study, we analyze one $17 \mathrm{~d}$ cycle of the Seasat orbit, using between 1000 and 2000 individual scatterometer measurements for each region.

\section{EMPIRICAL STUDY}

The back-scatter coefficient varies from -20 to $10 \mathrm{~dB}$ in the whole data set. The correlations of the back-scatter coefficient with various parameters and the behavior of the data in the four regions are analyzed successively as a function of incidence, azimuth angle and polarization. In what follows, only data with signal to noise $(\mathrm{S} / \mathrm{N})$ values larger than $10 \mathrm{~dB}$, as measured by the instrument, are considered. Because little is known a priori about the signal, the main features are first identified and then discussed.

\section{Correlation with different parameters}

In Figure 5, in order to have a more complete sampling, we use the whole data set to study correlations of 


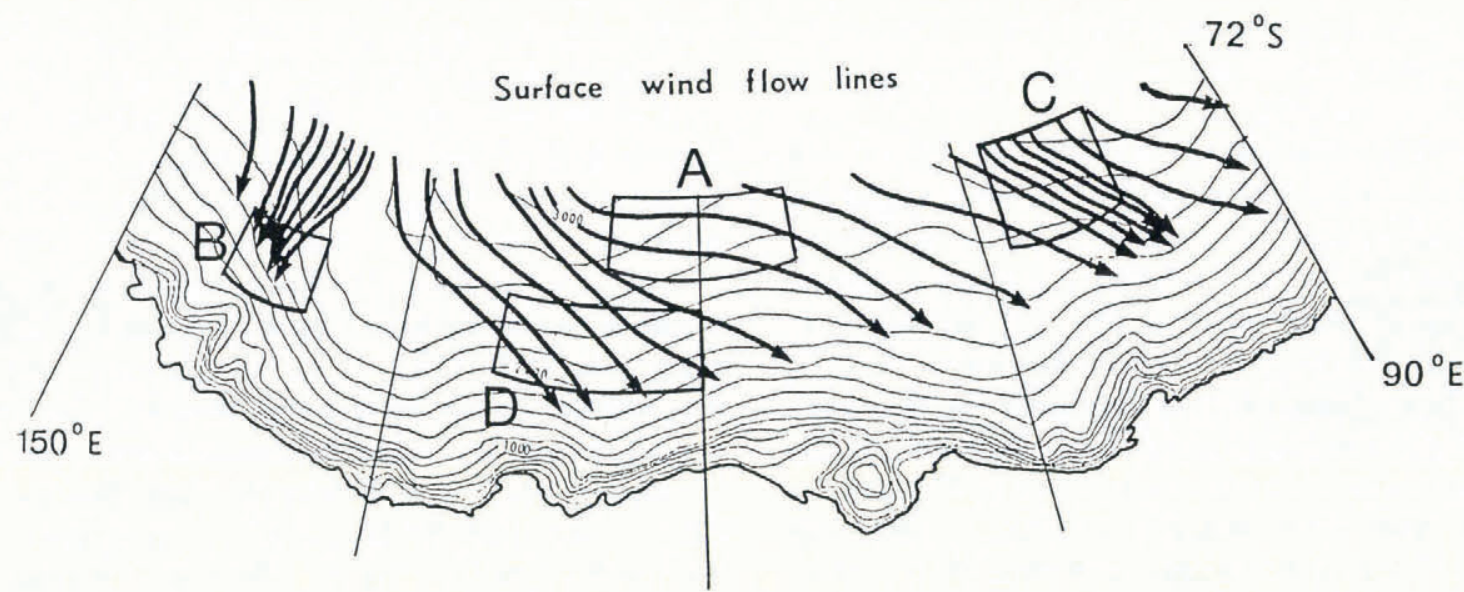

Fig. 3. Isolines of the topographic height of the Antarctic ice sheet (from Drewry, 1983) and flowlines of the model katabatic winds (from Parish, 1982). The four selected regions are indicated.

scatterometer data with the altimeter back-scatter coefficient, with altitude and with radiometric data at $37 \mathrm{GHz}$ measured by the Nimbus 7 SMMR (Scanning Microwave Radiometer) at $50^{\circ}$ incidence angle (vertical and horizontal emissivities $e_{v}$ and $e_{h}$, respectively, and the difference between both polarizations). The results are considered significant when the correlation coefficient exceeds 0.4 , which means that more than $16 \%$ of the signal can be explained by the correlation. They are as follows:

(i) The scatterometer back-scatter coefficient is correlated strongly with that of the altimeter at low incidence. As already observed for altimetry (Remy and Minster, 1991), the signal at low incidence angle is correlated strongly with the polarization of the emissivity. This effect, due to the presence of microroughness, disappears at higher incidences.

(ii) We do not observe any correlation with altitude. On the other hand, a significant correlation exists between the back-scatter coefficient and horizontal and vertical emissivity for "large" incidence angles.

The correlation with emissivity, a parameter connected with snow grain-size, would suggest the possible effect of a volume echo; however, this is in contradiction to the absence of correlation with altitude (or with temperature; snow grain-size, being temperature dependent, is related to altitude). In addition, the correlation with emissivity could be explained by surface roughness for horizontal polarization, but not for vertical polarization (Tsang and Newton, 1982). Because of this, further analyses were performed in the four regions.

\section{Polarization versus incidence angle}

Polarization of the back-scatter coefficient is shown as a function of incidence angle (Fig. 1) for the four regions (Fig. 6). Note that because the surface slope is less than $0.2^{\circ}$, even for region $\mathrm{B}$, its effect on the position of the pixel is much smaller than the size of the illuminated domains. As a consequence, the incidence angle as measured on board the satellite does not need to be corrected for surface-slope effects. The polarization is small and varies from -2 to $3 \mathrm{~dB}$. It is erratic at low and very large incidence angles. Otherwise, the signal for vertical polarization is slightly larger than for horizontal polarization and the difference tends to increase with incidence angle.

\section{Back-scatter coefficient versus incidence angle}

The variations of the back-scatter coefficient versus incidence angle for the four regions are shown in Figure

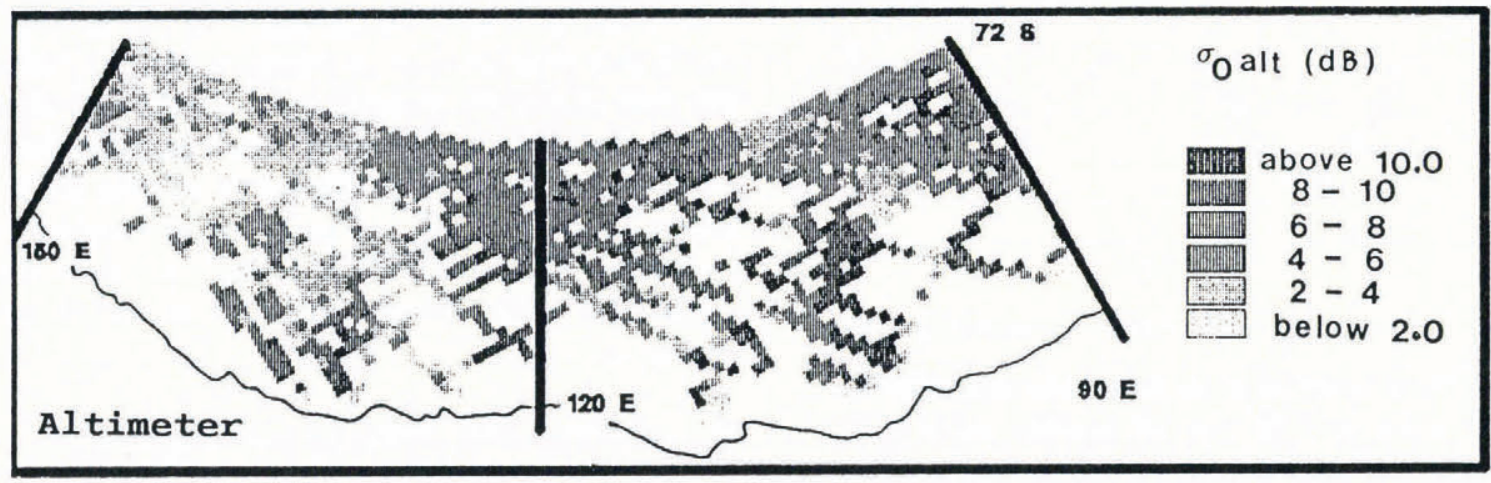

Fig. 4. Geophysical variations of the back-scatter coefficient measured by the Seasat altimeter (adapted from Remy and others, 1990). 


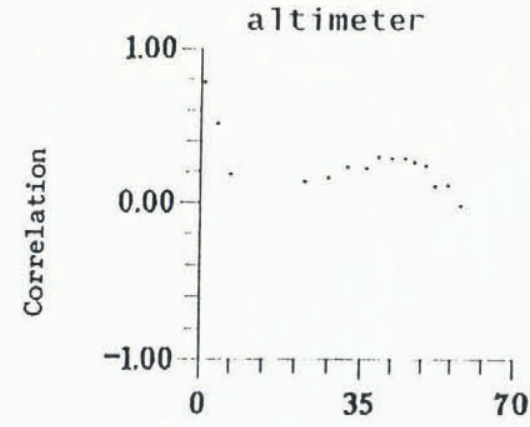

Incidence angle

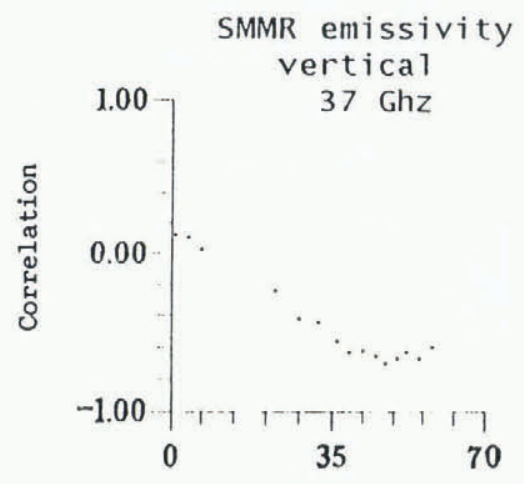

Incidence angle

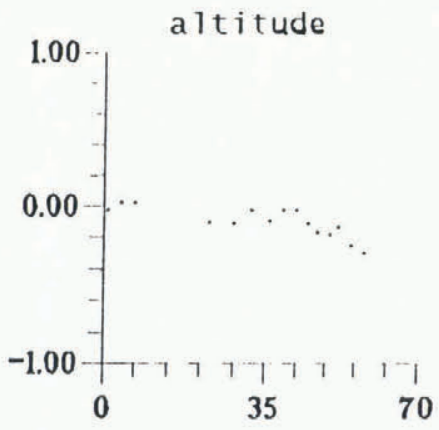

Incidence angle

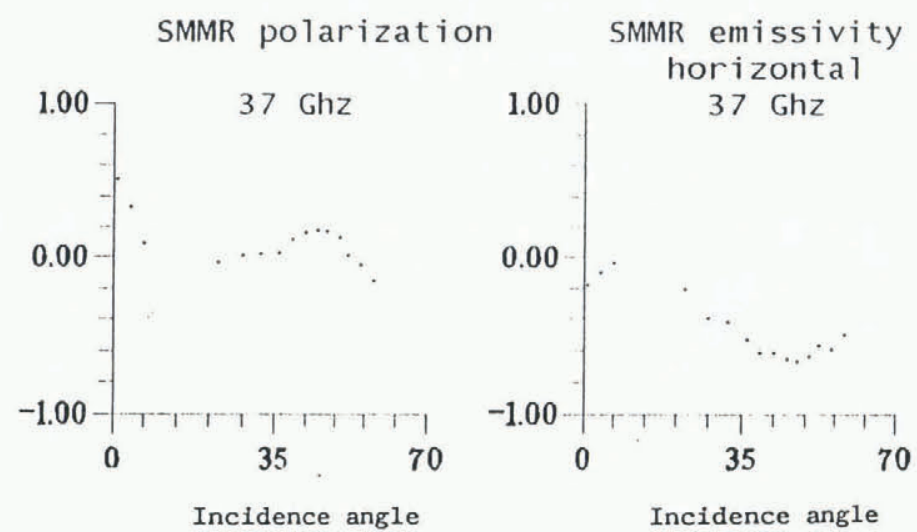

Fig. 5. Correlation of the scatterometer back-scatter coefficient with the Seasat altimeter $\sigma_{0}$, with altitude, with emissivities at $37 \mathrm{GHz}$ and $50^{\circ}$ incidence angle deduced from the Nimbus 7 SMMR data and with polarization of the latter signal.

7. Data for the two polarizations are used simultaneously. The signal is strongest in the vertical and decreases with incidence angle towards a steady value. However, for a given incidence angle, the back-scatter signal fluctuates by as much as $10 \mathrm{~dB}$. Regions $\mathrm{A}, \mathrm{C}$ and $\mathrm{D}$ have similar characteristics, whereas, in region $B$, the signal is lower by $4 \mathrm{~dB}$ at low incidence angles and higher by the same amount at large incidence angles. Only surface-scattering can explain this decrease with respect to incidence angle, as discussed later.

\section{Back-scatter coefficient versus azimuth angle}

The variations of the back-scatter signal minus the average back-scatter intensity for each cell (called the residual back-scatter coefficient) versus azimuth angle are shown in Figure 8. Although it is not complete, the distribution of azimuth is sufficient for observing that the residual back-scatter coefficient varies from -5 to $5 \mathrm{~dB}$, with well-defined minima and maxima. As in the case of the ocean, a bi-sinusoidal curve is shown in Figure 8. It is specified by

$$
\sigma / \sigma_{\text {moy }}=1+a \cos \left[2\left(\Phi-\Phi_{0}\right)\right]
$$

where $\sigma$ is the back-scatter coefficient and $\sigma_{\text {moy }}$ is the back-scatter coefficient averaged for each cell. $\Phi$ is the azimuth of observation and $\Phi_{0}$ that of the minimum. The coefficients $a$ and $\Phi_{0}$ were estimated by least-squares regression. Although the azimuth sample is well distributed for the whole data set, this is not the case for each cell; thus $\sigma_{\text {moy }}$ is re-estimated after a first iteration on $a$ and $\Phi_{0}$. The final results are given in Table 1 .

The fit to the model is estimated by a normalized, reduced $\sqrt{\chi^{2}}$, defined as

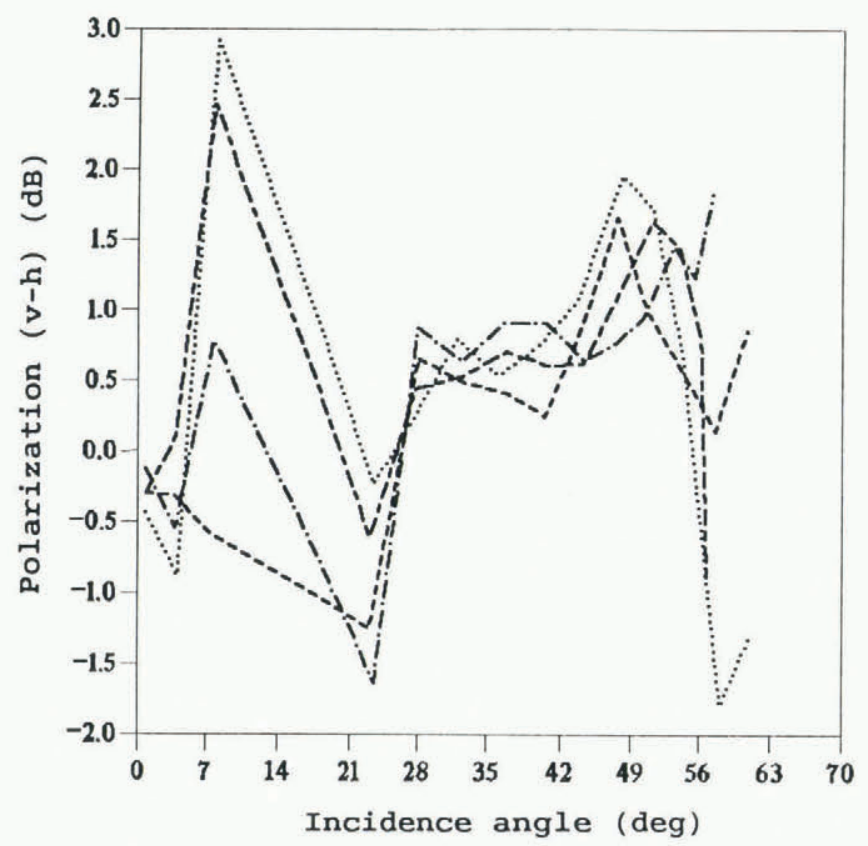

Fig. 6. Polarization of the scatterometer signal (in $d B$ ) as a function of incidence angle. The dotted line represents the reference curve of region $A$, fitted by averaging the values for each cell. 

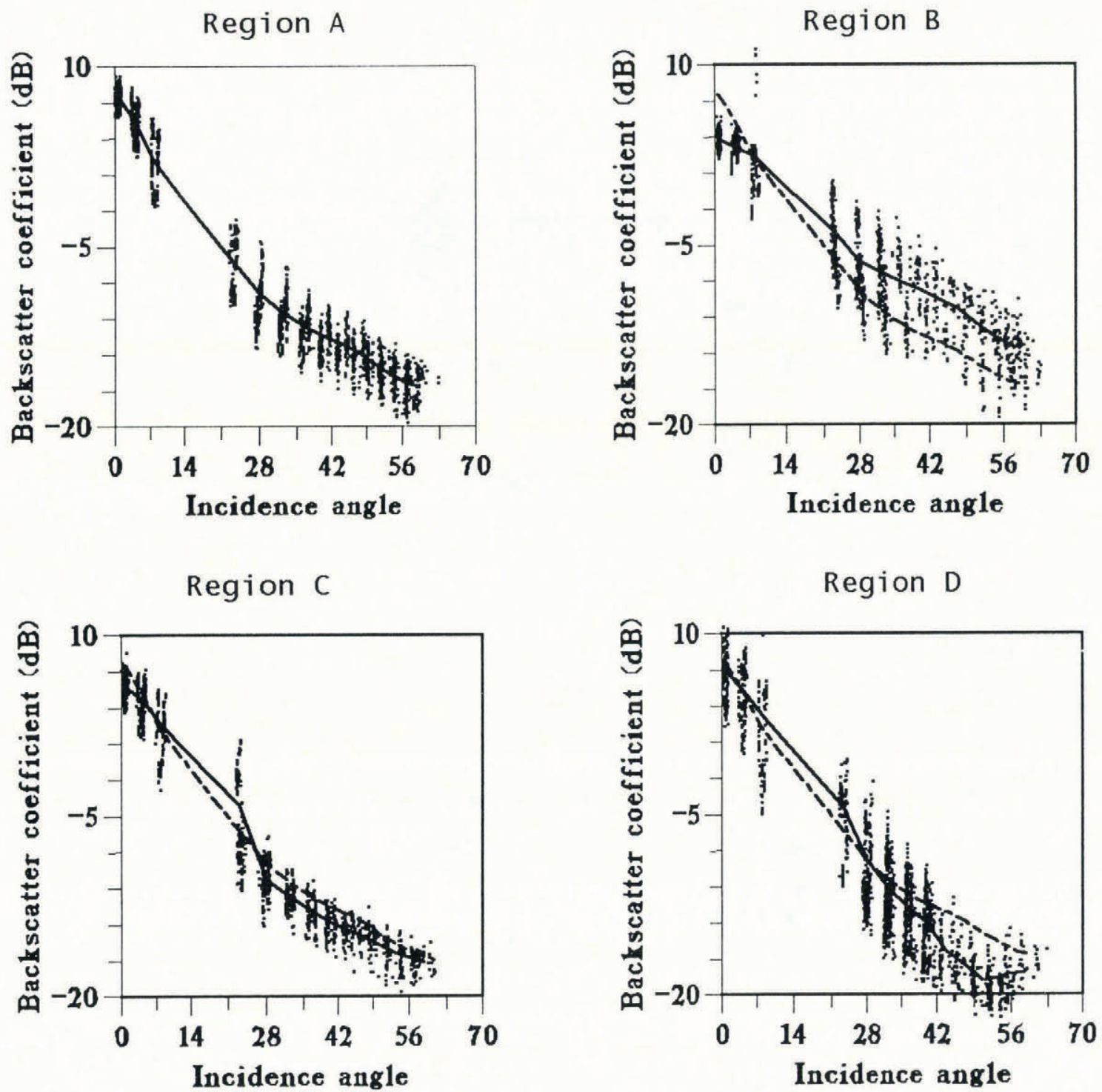

Fig. 7. Back-scatter coefficient as a function of incidence angle (in degrees) for the four regions. The continuous lines join the mean values for each cell. The dotted line is the line for region $A$, used as a reference.

$$
\chi^{2}=1 /(N-3) \sum_{n=1}^{N}\left(\left(\sigma_{n}^{\text {data }}-\sigma^{\text {model }}\left(\Phi_{n}\right)\right) /\left(\sigma_{n}^{\text {data }} / 10\right)\right)^{2} .
$$

In this calculation, $N$ is the number of data, $\sigma^{\text {model }}$ is calculated from Equation (1) for the azimuth value $\Phi_{n}$ of the datum. The normalization corresponds to $\mathrm{S} /$ $\mathrm{N}=10 \mathrm{~dB}$. In principle, $\chi^{2}$ should be close to 1 if the model fits the data. It is generally on the order of 4 , which is acceptable, but larger for region $\mathrm{D}$. Much spreading for this region is shown in Figure 8.

The parameter $a$ is largest for region $\mathrm{B}$, which has the strongest wind. It induces a signal of $5 \mathrm{~dB}$ amplitude, which is indeed close to observations. $\Phi_{0}$, the azimuth angle for maximum amplitude, is always at about $90^{\circ}$ from the wind direction, as determined independently from the katabatic-wind flowlines (Parish, 1982; Parish and Bromwich, 1991; Fig. 3).

Finally, region B data were analyzed by separating them according to polarization and incidence angle (we used three sets of four cells from numbers $1-4,5-8$ and 912). In each case, the variation with azimuth was similar.
Table 1. Variation of the residual back-scatter coefficient versus azimuth angle. $a$ and $\Phi_{0}$ are coefficients from Equation (1) adjusted by least-squares regression. $\Phi_{\mathrm{w}}$ is the azimuth of katabatic winds deduced from Figure 4. $\sqrt{\chi^{2}}$ is the reduced $\chi^{2}$ of the fit between Equation (1) and the data normalized to data noise. The regions are characterized according to wind intensity and altitude

\begin{tabular}{ccccccc}
$\begin{array}{c}\text { Region } \\
\end{array}$ & $\begin{array}{c}\text { Altitude } \\
\text { rank }\end{array}$ & $\begin{array}{c}\text { Wind } \\
\text { rank }\end{array}$ & $a$ & $\Phi_{0}$ & $\Phi_{\mathrm{w}}$ & $\sqrt{\chi^{2}}$ \\
& & & & & & \\
& & & & & $\operatorname{deg}$ & \\
\hline & & & & & & \\
A & 1 & 4 & 0.22 & 20 & 100 & 3.48 \\
B & 4 & 1 & 0.51 & 90 & 0 & 4.85 \\
C & 1 & 3 & 0.25 & 42 & 130 & 4.48 \\
D & 3 & 2 & 0.43 & 26 & 100 & 7.36
\end{tabular}



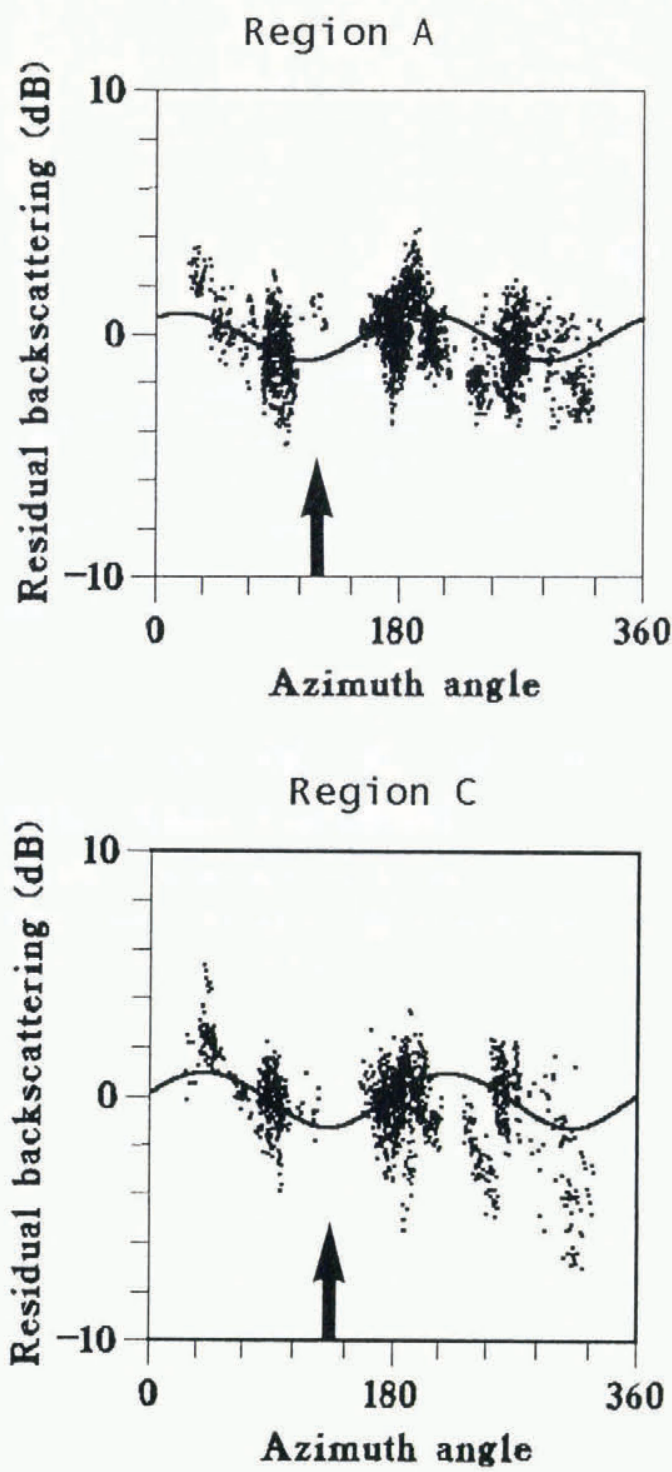
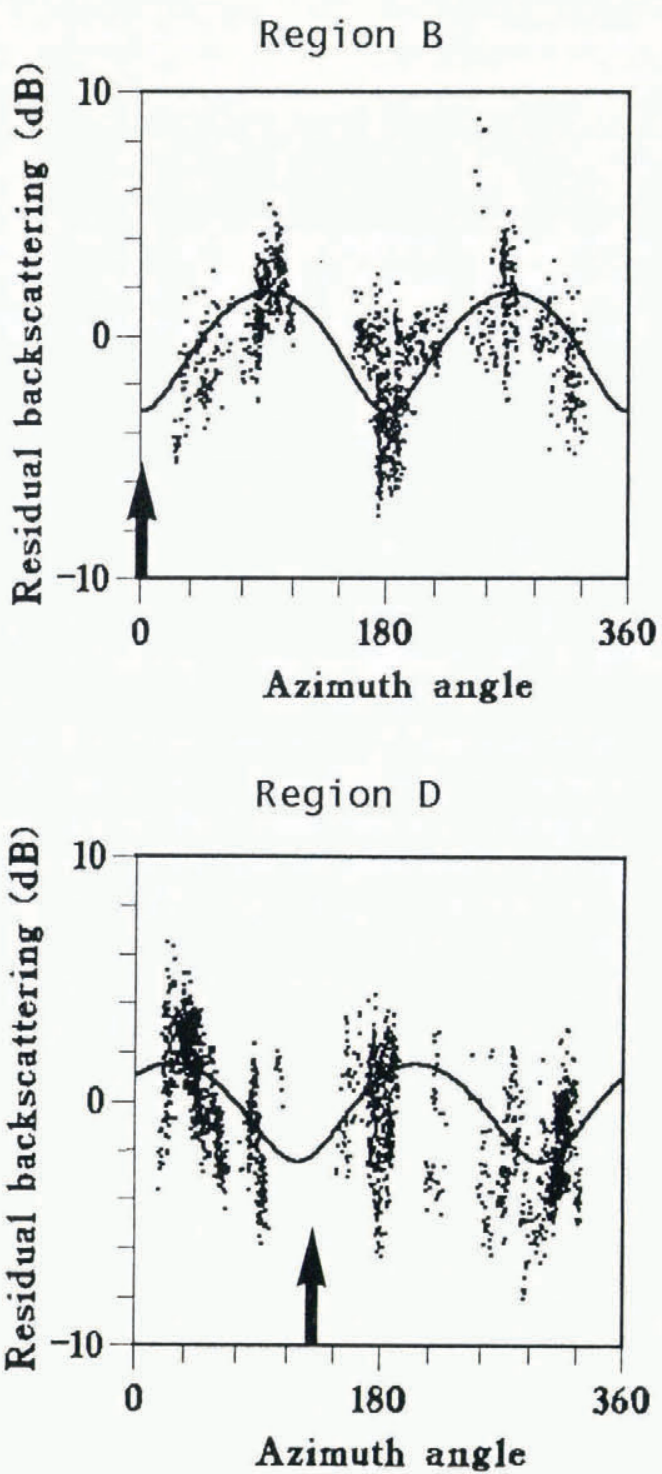

Fig. 8. Residual back-scatter coefficient (in $d B$ ) as a function of azimuth (in degrees) for the four regions. The residues are calculated for each cell by subtracting the mean value. The model curves corresponding to Equation (1), with the parameters of Table 1, are shown for comparison. The arrows indicate the azimuth of the model katabatic winds of Parish (1982).

\section{Discussion}

As a whole, the signal over ice is very similar to that above the ocean (Stewart, 1985; Fig. 2). The strong decrease of the back-scatter coefficient at low incidence suggests a surface effect, because the variations in the case of a volume echo would be small. The variations in residual back-scatter with azimuth at all incidence angles again suggests a surface-roughness effect. It would be necessary that the reflecting features be orientated in the wind direction for the back-scatter to be minimum in that direction. This is the case for sastrugi. They are streamlined ridges formed on the snow surface by the wind and are orientated in the wind direction (Parish and Bromwich, 1987; Bromwich and others, 1990).

Region B differs from the other three regions. It has a lower signal at low incidence angles, a stronger signal at strong incidence angles and a larger sensitivity to azimuth. All three features are coherent with a surfaceroughness effect, as B is the region of strongest winds.

Finally, a surface effect could explain the large variations of the signal at low incidence angle (Fig. 7).
These variations could be due to measurement effects, such as propagation of the radar wave in the atmosphere, or to actual signal variations. It would be surprising if atmospheric effects, which can indeed reach $10 \mathrm{~dB}$, only affect measurements at low incidence angles. On the other hand, Remy and others (1990) showed that surface undulations with a $20 \mathrm{~km}$ distance scale could induce variations in the altimeter returned power of about $10 \mathrm{~dB}$, which is of the same order as observed here.

However, polarization is weak, whereas the surfaceroughness effect should have an influence. In addition, we have already mentioned that surface roughness should not affect emissivity at the vertical polarization. In any case, it is desirable to analyze the potential effects of the surface and sub-surface snow state more quantitatively. This is the object of the following section.

\section{THEORETICAL STUDY}

In order to analyze more quantitatively whether the observed signals can be explained by the known ranges of 
the critical parameters, a simple discussion of two models for volume and surface echos is presented.

\section{Volume echo}

Theoretical models of volume-scattering by snow are based on Rayleigh's radiative-transfer method. The volume diffusion per surface unit is written (Rott, 1984, 1985):

$$
\begin{aligned}
\sigma_{\mathrm{vol}}= & \frac{\epsilon_{0}}{\epsilon_{1}} t^{2}\left[\frac{\delta k_{1}^{4} l_{\mathrm{z}} l_{\mathrm{r}}^{2}}{4 k_{\mathrm{a}}}\right] \frac{\cos ^{2} \theta}{\cos ^{2} \theta_{\mathrm{t}}}\left[\frac{1}{1+4 k_{l}^{2} l_{z}^{2} \cos ^{2} \theta_{\mathrm{t}}}\right] \\
& \cdot \exp \left(-k_{l}^{2} l_{\mathrm{r}}^{2} \sin ^{2} \theta_{\mathrm{t}}\right)
\end{aligned}
$$

where $l_{\mathrm{r}}$ and $l_{z}$ are correlation lengths of snow, corresponding to the average of the grain-size (Vallese and Kong, 1981), which we will take as spherical $\left(l_{\mathrm{r}}=l_{z}\right) . \epsilon_{1}$ is the permittivity for snow. Its value depends on snow density as $\epsilon_{1}=1+1.7 \rho+0.7 \rho^{2}$. As $\rho$ varies from 0.35 to $0.45 \mathrm{Mg} \mathrm{m}^{-3}, \epsilon_{1}$ varies from 1.68 to 1.91 . $\epsilon_{0}$ is equal to $1 . \delta k$ is the permittivity fluctuation of snow and is taken at 0.24 (Vallese and Kong, 1981). $t$ is the transmittivity; in this case, it has a value of $1 . \theta$ is the incidence angle. $\theta_{\mathrm{t}}$ is the angle of transmission, related to $\theta$ by Snell's law of refraction: $\sin \theta_{\mathrm{t}}=\sqrt{\epsilon_{1}} \sin \theta . k_{1}$ is the wave number in the medium, where $k_{1}=2 \pi / \lambda, \lambda$ is the radar wavelength, that is $2.3 \mathrm{~cm}$ for Seasat. $K_{\mathrm{a}}$ is the volume-absorption coefficient, which depends on the dielectric constant and varies between 0.05 and 0.2 according to Ulaby and Styles (1980) and Mätzler (1987). Here, we take the value $K_{\mathrm{a}}=0.2$ because values below this are too low to explain the radiometric observations (Rott, 1989).

The first bracket within Equation (3) is independent of incidence angle and only has an effect on the signal intensity. It varies with the absorption coefficient or with permittivity fluctuations. However, it is most sensitive to grain-size as it depends on the cube of $l_{\mathrm{r}}$. The second term is a function of the incidence angle. The curvature of back-scatter coefficient versus incidence angle varies with snow-grain radius and permittivity.

Back-scatter values, changing from -37 to $-18 \mathrm{~dB}$ for $l_{\mathrm{r}}$ values varying from 0.3 to $1 \mathrm{~mm}$ (Gow, 1960), are shown in Figure 9. At large incidence angles, the theoretical intensity is comparable to the experimental data of Figure 8. However, the fit is not good at low incidence angles. Thus, volume diffusion alone does not seem to explain the observations. Of course, at this stage, the effects of multiple scattering or of complex layering cannot be excluded.

\section{Surface echo}

When an incident wave intersects a smooth surface, the reflected signal is principally a coherent or specular component, which is directional. The rougher the surface, the higher the diffuse component and the less coherent the echo. The surface roughness will be characterized either by its correlation length $L$ and its root-mean-square (r.m.s.) height $\sigma_{\mathrm{L}}$, or instead by its r.m.s. surface slope, $m$. Roughness is to be compared with the wavelength of the radar signal $\lambda$. The echo model will depend on the value of $k_{1} \sigma_{\mathrm{L}}=(2 \pi / \lambda) \sigma_{\mathrm{L}}$. The effect of a rough surface on the

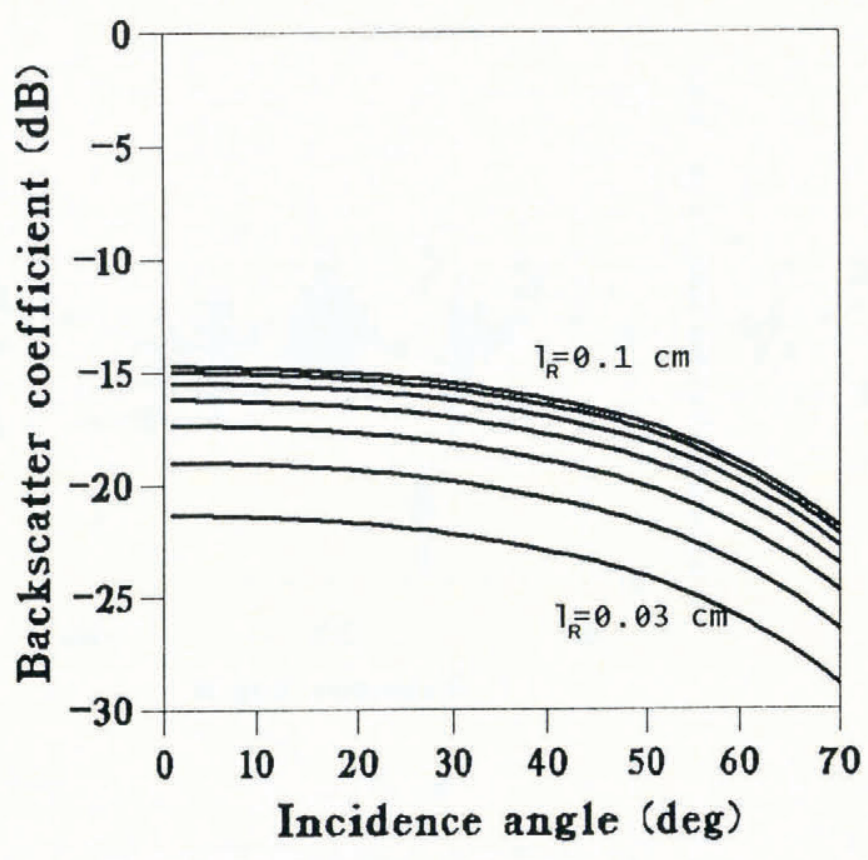

Fig. 9. Variations of the back-scatter coefficient as a function of incidence angle in the case of volume-scattering. The curves are shown for various grain-sizes $l_{r}$ from 0.3 to $1 \mathrm{~mm}$.

scattered power is analyzed in different cases, as in Fung (1984). We consider only the extreme cases, the intermediate one being more complex.

According to Fung (1984), if a strong variation of the back-scatter coefficient is observed at low incidence angles, surface roughness is large compared with the radar wavelength, meaning that it is least a correlation length $L$ of the surface greater than $\lambda$ (which is $2.3 \mathrm{~cm}$ for Seasat). This case corresponds to $k_{1} \sigma_{\mathrm{L}}>3$. The intensity of the radar back-scatter coefficient is then proportional to the illuminated surface and takes the form (Fung, 1984)

$$
\sigma_{\mathrm{vv}}=\sigma_{\mathrm{hh}}=R^{2}(0) \sec ^{4} \theta p(\operatorname{tg} \theta)
$$

where $\theta$ is the incidence angle, and $R(0)$ is the Fresnel reflection coefficient at the vertical. $R(0)$ depends on $\epsilon$ : $R(0)=(\sqrt{\epsilon}-1) / \sqrt{\epsilon}+1)$ and is given the value of 0.145 . It varies from 0.129 to $0.16 . p(\operatorname{tg} \theta)$ is the probability density function of the surface slope. As an example, for a Gaussian slope distribution, the expression becomes

$$
\sigma_{\text {surf }}(\theta)=\left(R^{2}(0) / 2 m^{2} \cos ^{4} \theta\right) \exp \left(-t g^{2} \theta / 2 m^{2}\right) .
$$

At normal incidence angle, the expression becomes

$$
\sigma_{\text {surf }}(0)=R^{2}(0) / 2 m^{2} \text {. }
$$

The back-scatter coefficient versus incidence angle for different surface slope r.m.s. values varying from 0.05 to 0.5 , representing Equation (5), is shown in Figure 10 (Fung, 1984). The lower the slope r.m.s., the more intense the signal in the vertical and the stronger its decrease with incidence. Note that the range of values for $R(0)$ would correspond to a range of intensities of only $2 \mathrm{~dB}$.

If a signal is observed at large incidence angles, it means that the surface roughness is small compared with the radar wavelength. The surface is then usually called a 


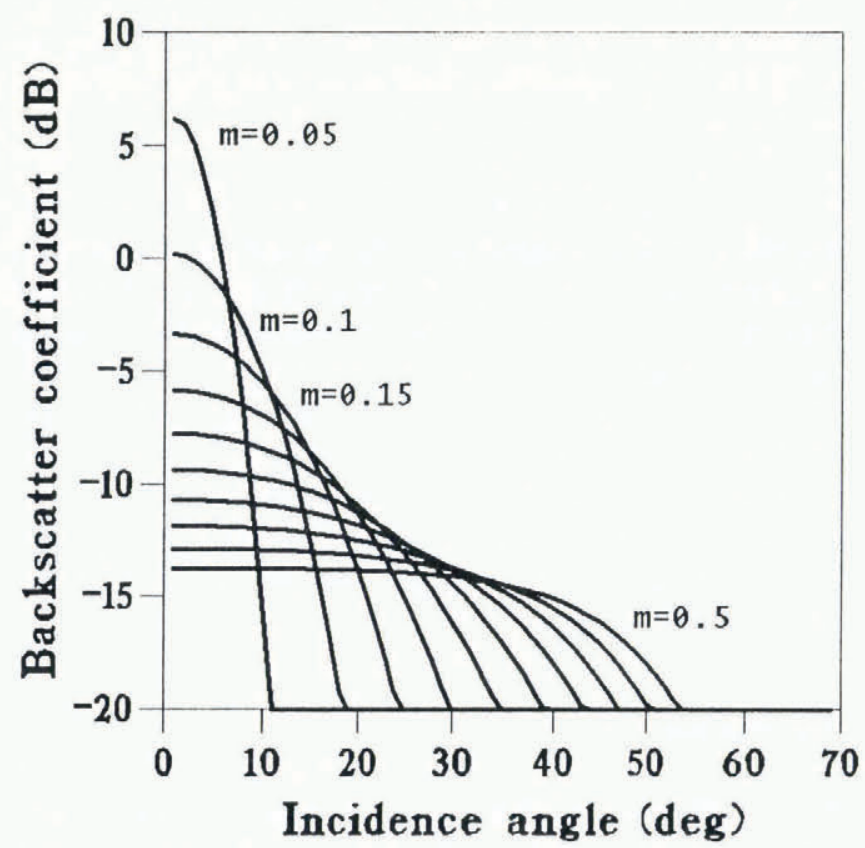

Fig. 10. Variations of the back-scatter coefficient as a function of incidence angle in the case of scattering by $a$ large-scale roughness element. The curves are shown for various r.m.s. slopes of the roughness $(m)$ from 0.05 to 0.5 (intervals of 0.05 ).

slightly rough surface of r.m.s. height $\sigma_{1}$. It exists at least a correlation length $l$ of the surface features smaller than the wavelength. This case corresponds to $k_{1} \sigma_{1}<3$. If some terms related to diffraction are neglected and incidence angles are larger than $25^{\circ}$, the back-scatter coefficient is written (Fung, 1984)

$$
\sigma_{\text {surf }}(\theta)=8 k_{1}^{4} \sigma_{1}^{2} \cos ^{4} \theta R_{\mathrm{p}}^{2} W\left(2 k_{1} \sin \theta\right),
$$

$p$ being the polarization (vertical or horizontal) and $R_{\mathrm{p}}$ the Fresnel coefficient. For horizontal polarization (Fung, 1984)

$$
R_{\mathrm{h}}=\left(\left(\epsilon-\sin ^{2} \theta\right)^{0.5}-\cos \theta\right) /\left(\left(\epsilon-\sin ^{2} \theta\right)^{0.5}+\cos \theta\right) .
$$

For vertical polarization (Fung, 1984)

$$
\begin{aligned}
R_{\mathrm{v}}= & (\epsilon-1)\left(\sin ^{2} \theta-\epsilon\left(1+\sin ^{2} \theta\right)\right) \\
& /\left(\left(\epsilon-\sin ^{2} \theta\right)^{0.5}+\epsilon \cos \theta\right)^{2} .
\end{aligned}
$$

$W\left(2 k_{1} \sin \theta\right)$ represents the roughness spectrum; that is, the Fourier transform of the surface height autocorrelation. If an exponential function is taken for the latter, this gives

$$
W\left(2 k_{1} \sin \theta\right)=l^{2} / \pi\left(1+4 k_{1}^{2} l^{2} \sin ^{2} \theta\right) .
$$

The back-scatter coefficient is shown as a function of $\theta$ for $\sigma_{l}=1 \mathrm{~cm}, \epsilon=1.8$ and $l$ varying from 1.2 to $4 \mathrm{~cm}$ (Fig. 11). Remember that the model is only valid at large incidence angles. The shape of the curve is essentially insensitive to $l$. The signal is more intense as the correlation length $l$ decreases. Changing $\epsilon$ within its range of values affects the intensity of the signal by only incidence to $3 \mathrm{~dB}$ at $60^{\circ}$ incidence (Equations (8) and (9)). This is similar to the observations (Fig. 6). Note that Swift and others (1985) argued that volume echo is dominant at large incidences because the micro-roughness creates polarization, which is not observed in airborne microwave measurements. However, the dielectric constant of the dry snow is such that the polarization effect is weak.

\section{Towards a two-scale model for surface-echo roughness}

Variations of the back-scatter coefficient can be obtained for both small and large incidence angles. The large observed radar back-scatter intensity near the vertical is explained by a large-scale roughness model with a low surface slope r.m.s. ( $m$ of about $0.05 \mathrm{rad}$ ). On the other hand, in order to interpret the signal at large incidence angles, a small-scale roughness model is needed.

A two-scale roughness model is thus required, in which both micro-roughness and sastrugi would affect the radar echo. It is tempting to apply a two-scale roughness model, as for the ocean. We therefore use the theoretical model of Chan and Fung (1977), valid only for incidence angles greater than $30^{\circ}$ and designed for the ocean case.

In this model, the back-scatter coefficient $\sigma_{\mathrm{pp}}$ due to small-scale roughness, described as a slightly rough surface, is averaged over the tilt $\theta^{\prime}$ created by the largescale roughness.

$$
\begin{gathered}
\sigma_{\mathrm{pp}}^{0}\left(\theta, h-\Phi_{\mathrm{w}}\right)=\int_{-\infty}^{\infty} \int_{\omega t \theta}^{+\infty} \sigma_{\mathrm{pp}}\left(\theta^{\prime}, \Phi-\Phi_{\mathrm{w}}\right) \\
. P_{\theta}\left(Z_{x^{\prime}}, Z_{y^{\prime}}\right) \mathrm{d} Z_{x} \mathrm{~d} Z_{y}
\end{gathered}
$$

where $Z_{x}$ and $Z_{y}$ are the large-scale local surface slopes and $P_{\theta}\left(Z_{x^{\prime}}, Z_{y^{\prime}}\right)$ is the large-scale slope distribution. The primes correspond to a reference system where the $X^{\prime}$ axis

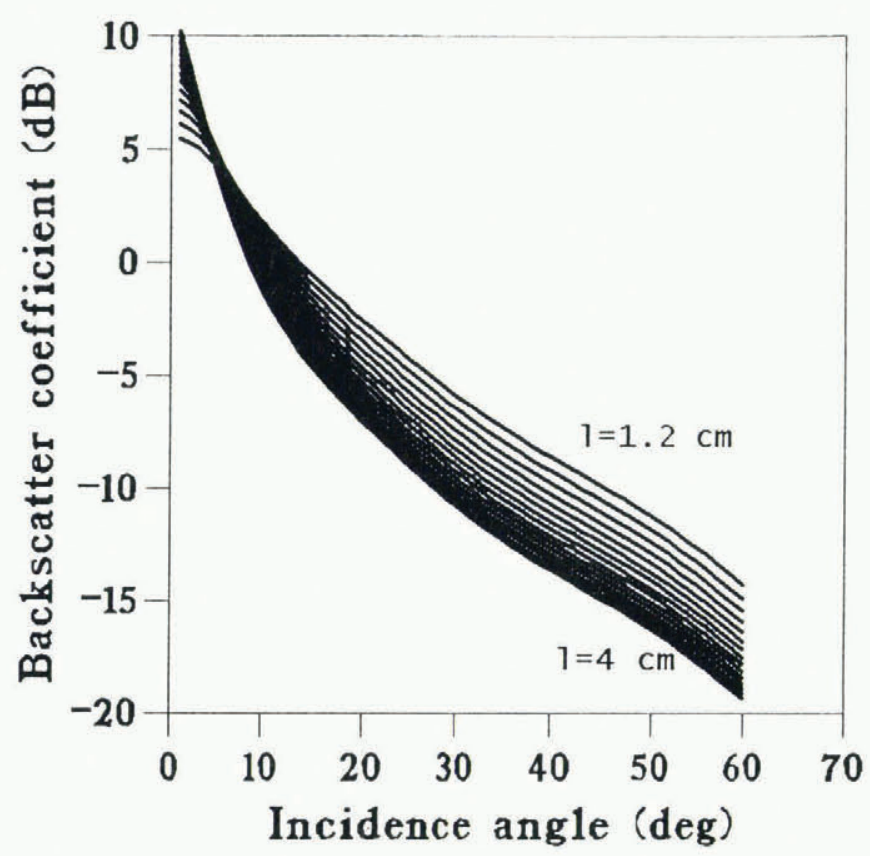

Fig. 11. Variations of the back-scatter coefficient with incidence angle in the case of back-scatter by a slightly rough surface. The model is only valid for $\theta$ larger than $25^{\circ}$. The curves are shown for a given r.m.s. height of the roughness $(\sigma=1 \mathrm{~cm})$ and for various length scales, $l$, from 1.2 to $4 \mathrm{~cm}$ (intervals of $0.2 \mathrm{~cm}$ ). 
is in the upwind direction, of azimuth $\Phi_{\mathrm{w}}$ relative to the $X$ axis.

In the case of Antarctica, the amplitude of the largescale roughness would correspond to sastrugi. It is of the order of $10 \mathrm{~cm}$ to $1 \mathrm{~m}$ on distance scales of about $10 \mathrm{~m}$. The corresponding slope would vary from $0^{\circ}$ to $6^{\circ}$. We will therefore neglect its effect, because it would correspond to a variation of the back-scatter coefficient of the order of only $1 \mathrm{~dB}$. (This approximation should be verified using in-situ measurements of the slope statistics of the ice surface.) Then

$$
\begin{aligned}
\theta & =\theta^{\prime} \\
\text { and } \quad \sigma_{\mathrm{pp}}\left(\theta, \Phi-\Phi_{\mathrm{w}}\right) & =\sigma_{\mathrm{pp}}\left(\theta^{\prime}, \Phi-\Phi_{\mathrm{w}}\right) .
\end{aligned}
$$

The back-scatter coefficient is that of the small-scale surface-roughness model (Equation (7)) and

$$
\sigma_{\mathrm{pp}}\left(\theta, \Phi-\Phi_{\mathrm{w}}\right)=8 k_{1}^{4} \sigma_{l}^{2} \cos ^{4} \theta R_{\mathrm{p}}^{2} W^{\mathrm{ice}}\left(K, \Phi-\Phi_{\mathrm{w}}\right)
$$

where $K=2 k_{1} \sin \theta$.

The spectrum for small-scale waves of the sea, the analogue of snow micro-roughness features, is known from observations and dynamical considerations. From this model spectrum, Chan and Fung (1977) derived the dependence of $W^{s e a}$ on azimuth as

$$
W^{\text {sea }}\left(K, \Phi-\Phi_{\mathrm{w}}\right)=W^{\text {sea }}(K)\left(1+a \cos 2\left(\Phi-\Phi_{\mathrm{w}}\right)\right)
$$

where $a$ is related to the ratio of the total slope variance across the wind direction to that up-wind.

Spectra for continental ice roughness are not available. However, as it is found experimentally that the back-scatter coefficient varies with azimuth as a bisinusoid (Fig. 8), the same functional dependence for $W^{\text {ice }}$ (Equation (1)) is assumed. Note that, contrary to the ocean, where $a$ is determined primarily by large-scale gravity waves, small-scale roughness may dominate the slope variances (in agreement with the previous simplifications for the calculation of $\sigma_{\mathrm{pp}}{ }^{0}$ ).

The adjustments to the data were achieved as follows:

(i) The dependence on the azimuth was derived in each region from all data, including both polarizations and all incidence angles. This was done because the number of azimuth values is small for a given incidence angle and because no significant difference is found for region B when the data set is split according to these parameters.

(ii) In the formula for the high incidence angle, smallscale roughness effect (Equation (7)), $\sigma_{l}$ was fixed at $1.5 \mathrm{~cm}$ and $l$ estimated by a least-squares fit to the observations. Only incidence angles larger than $25^{\circ}$ were used (cells 1-12) and the calculations were done separately for each polarization. For $\theta>25^{\circ}$, a variation of $l$ only changes the intensity of the backscatter coefficient and not the shape of the curve (Fig. 13). As $\sigma_{l}$ is a multiplicative constant, it would have the same effect. Thus, only the $\sigma_{l}^{2} / l$ ratio can be estimated.

(iii) Finally, using the large-scale roughness model (Equation (5)), the r.m.s. slope $m$ was adjusted to the low incidence-angle data (cells 13-15). Of course, this is an approximation, because small-scale roughness also affects these values. However, the two effects are likely to be correlated. The results are summarized in Table 2.

The $\sigma_{l}^{2} / l$ values for both polarizations are very consistent. They suggest that the typical scale height of roughness is twice as large for region $\mathrm{B}$ than for the other regions (or alternatively that its length scale is less by half). The r.m.s. slope $m$ varies accordingly. For a feature of $1 \mathrm{~m}$ scale height, its value implies a length scale of $6 \mathrm{~m}$ for region $\mathrm{B}$ and of $12 \mathrm{~m}$ for regions $\mathrm{A}$ and $\mathrm{D}$. This is consistent with typical scales for sastrugi. Note that aerial surveys of sastrugi typically report longer sastrugi than ground surveys, with length between 10 and $200 \mathrm{~m}$ (Bromwich and others, 1990).

\section{Discussion}

Both surface-scattering at all incidence angles and volume-scattering at large incidence angles could explain the observations quantitatively. Note, however, that the surface and snow parameters should be correlated if both processes control the signal. It would be necessary for grain-size to be larger in areas of strong wind intensity to explain the larger signal in region $\mathrm{B}$ at large incidence, and the correlation with emissivity at vertical polarization, by a volume-scattering effect. If this is the case, parameters for surface roughness and katabatic winds can be derived empirically using Equations (5) and (12). Note that " $a$ " varies closely with the wind intensity (Table 1). The more intense is the wind, the more important the variations with the azimuth of observation relative to the wind direction. This leads us to argue that " $a$ " is related to sastrugi, because these surface features increase in height with wind intensity (Drewry and others, 1985). On the other hand, $m$ and $\sigma^{2} / l$ do not appear to be related to wind intensity alone (Table 2), except for region B where the greater wind intensity will correspond to the higher values of these parameters. For the other cases, the value of $m$ is not really distinct.

In any case, it would be necessary to study the

Table 2. Roughness parameters as deduced by least-squares regression from the data. $m$ is the r.m.s. surface slope, $\sigma_{l}$ is the height r.m.s. for small-scale roughness and $l$ the corresponding length scale. The regions have been ranked as in Table 1

\begin{tabular}{cccccc} 
Region & $\begin{array}{c}\text { Altitude } \\
\text { rank }\end{array}$ & $\begin{array}{c}\text { Wind } \\
\text { rank }\end{array}$ & $m$ & $\begin{array}{c}\sigma_{l}^{2} / l \\
\text { horizontal }\end{array}$ & $\begin{array}{c}\sigma_{l}^{2} / l \\
\text { vertical }\end{array}$ \\
& & & & $\mathrm{cm}$ & $\mathrm{cm}$ \\
\hline & & & & & \\
A & 1 & 4 & 0.08 & 0.4 & 0.3 \\
B & 4 & 1 & 0.16 & 1 & 0.7 \\
C & 1 & 3 & 0.1 & 0.4 & 0.3 \\
D & 3 & 2 & 0.08 & 0.25 & 0.3
\end{tabular}


statistics of the snow and its associated roughness parameters to develop more quantitative models of the scatterometer signal. Moreover, significant effects can be due to sub-surface layering, which may very well appear to simulate surface effects.

\section{CONGLUSION}

Above Antarctica, the back-scatter coefficient at $14.6 \mathrm{GHz}$, as measured by the Seasat scatterometer, varies in a way similar to that measured for the oceans. It decreases with incidence angle from 10 to $-20 \mathrm{~dB}$, and shows a signal of about $+5 \mathrm{~dB}$ with the azimuth of observation relative to the wind direction (cf. Figs 2, 7 and 8). An important difference with the ocean case lies in the polarization of the signal, which is very small above ice (of the order ot $3 \mathrm{~dB}$ at most; Fig. 6), whereas it is larger than $10 \mathrm{~dB}$ above the ocean at high incidence angles (Fig. 2).

Simplified models of volume and surface back-scatter suggest that this signal could be explained by an effect of the latter. At low incidence angle, the signal depends mostly on the quadratic mean slope of the medium-scale surface features. Values of 0.08 to 0.16 are found, which can result from micro-roughness, sastrugi and snow dunes. The observed strong decrease of the signal with incidence angle completes the analysis of Remy and Minster (1991), who used the altimeter measurements in the vertical. At high incidence angles (above $25^{\circ}$ ), the signal would be dominated by micro-roughness. A characteristic parameter $\sigma_{1}^{2} / l$ can be estimated, where $\sigma_{l}$ is the r.m.s. height and $l$ is the length scale of microroughness. It varies from 0.3 to $1 \mathrm{~cm}$ and increases with the intensity of katabatic winds.

Unfortunately, the signal at high incidence angles could be explained as well by a volume back-scatter, provided the snow grain-size increases with surface-wind speed. In addition, this study cannot distinguish between pure surface effects and back-scatter from sub-surface layerings.

This preliminary study suggests that scatterometer observations above ice sheets provide an empirical mapping of roughness on various scales and may possibly lead to the identification of the surface-wind intensity and direction. This could be the first possible way to map the average surface winds in large, unmonitored areas of the continental ice sheets.

However, it also seems necessary to document the spectral characteristic of the surface roughness, as a function of wind speed and other parameters, in order to understand this relationship. In addition to in-situ measurements, a more advanced model of the backscatter is required. Such models now exist for the altimeter and for the scatterometer over land or vegetation. They should be easy to adapt to continental ice.

In any case, it would be interesting to obtain data for the back-scatter coefficient in various seasons and above all of the ice sheets. Thanks to sufficient power aboard the platform, the European Space Agency (ESA) recently decided to leave the ERS-1 scatterometer on over the whole Earth. This will provide dense, almost complete daily coverage of the Antarctic ice sheet with observations at many azimuth angles at each location. The instrument being in the $\mathrm{C}$ band rather than the $\mathrm{KU}$ band of the Seasat scatterometer, should diminish the volume effect by up to $15 \mathrm{~dB}$. A number of our estimates will have to be re-evaluated, particularly with regard to the effects of micro-roughness. Very interesting results are to be expected from this data set.

\section{ACKNOWLEDGEMENTS}

We are grateful to Dr D. Bromwich for his many comments and suggestions in his review of this paper.

\section{REFERENGES}

Bracalente, E. M., D. H. Buggs, W.L. Grantham and J.L. Sweet. 1980. The SASS scattering coefficient $\sigma_{0}$ algorithm. IEEE 7. Oceanic Eng., OE-5, 145-154.

Bromwich, D.H., T.R. Parish and C.A. Zorman. 1990. The confluence zone of the intense katabatic winds at Terra Nova Bay, Antarctica, as derived from airborne sastrugi surveys and mesoscale numerical modeling. 7 . Geophys. Res., 95(D5), 5495-5509.

Chan, H. L. and A.K. Fung. 1977. A theory of sea scatter at large incident angles. 7. Geophys. Res., 82(24), 3439-3444.

Drewry, D.J. 1983. The surface of the Antarctic ice sheet. In Drewry, D.J., ed. Antarctica: glaciological and geophysical folio. Cambridge, Scott Polar Research Institute, Sheet 2.

Drewry, D. J., N.F. McIntyre and P. Cooper. 1985. The Antarctic ice sheet: a surface model for satellite altimeter studies. In Woldenberg, H.J., ed. Models in geomorphology. Boston, MA, etc., Allen and Unwin, 123.

Fung, A. K. 1984. Surface scattering effects at different spectral regions. Colloques INRA 23, 693-705.

Fung, A. K. and H.J. Eom. 1982. Application of a combined rough surface and volume scattering theory to sea ice and snow backscatter. IEEE Trans. Geosci. Remote Sensing, GE-20(4), 528-536.

Gow, A.J. 1960. On the rates of growth of grains and crystals in South Polar firn. 7. Glaciol., 8(53), 241-252.

Johnson, J. W., L.A. Williams, E. M. Bracalente, F. B. Beck and W. L. Grantham. 1980. Seasat-A satellite scatterometer instrument evolution. IEEE 7 . Oceanic Eng., OE-5, 138-144.

Mätzler, C. 1987. Applications of the interaction of microwaves with the natural snow cover. Remote Sensing Rev., 2(2), 259-392.

Parish, T. R. 1982. Surface airflow over East Antarctica. Mon. Weather Rev., 110, 84-90.

Parish, T.R. and D.H. Bromwich. 1987. The surface windfield over the Antarctic ice sheets. Nature, 328(6125), 51-54.

Parish, T.R. and D.H. Bromwich. 1991. Continentalscale simulation of the Antarctic katabatic wind regime. 7. Climate, 4, 135-146.

Remy, F. and J. F. Minster. 1991. A comparison between active and passive microwave measurements of the 
Antarctic ice sheet and their association with the surface katabatic winds. F. Glaciol., 37(125), 3-10.

Remy, F., P. Mazzega, S. Houry, C. Brossier and J. F. Minster. 1989. Mapping of the topography of continental ice by inversion of satellite-altimeter data. 7. Glaciol., 35(119), 98-107.

Remy, F., C. Brossier and J. F. Minster. 1990. Intensity of satellite radar-altimeter return power over continental ice: a potential measurement of katabatic wind intensity. 7. Glaciol., 36(123), 133-142.

Rotman, S. R., A. D. Fisher and D.H. Staelin. 1982. Inversion for physical characteristics of snow using passive radiometric observations. F. Glaciol., 28(98), 179-185.

Rott, H. 1984. The analysis of backscattering properties from SAR data of mountain regions. IEEE $\mathcal{F}$. Oceanic Eng., OE-9, 347-355.

Rott, H. 1989. Multispectral microwave signatures of the Antarctic ice sheet. In Pampaloni, P., ed. Microwave radiometery and remote sensing applications. Utrecht, VSP, 89-101.

Rott, H., G. Domik, C. Mätzler, H. Miller and K. G. Lenhart. 1985. Study on use and characteristics of SAR for land snow and ice applications. Final report. Paris, European
Space Agency. (ESA Report 5441/83/D/IM/SC.)

Stewart, R.H. 1985. Methods of satellite oceanography. La Jolla, CA, Scripps Institution of Oceanography.

Stiles, W.H. and F.T. Ulaby. 1980. The active and passive microwave response to snow parameters, I. Wetness. J. Geophys. Res., 85(2), 1037-1044.

Swift, C. T., P.S. Hayes, J. S. Herd, W. L. Jones and V.E. Delnore. 1985. Airborne microwave measurements of the southern Greenland ice sheet. F. Geophys. Res., 90(B2), 1983-1994.

Tsang, L. and R. W. Newton. 1982. Microwave emissions from soils with rough surfaces. 7. Geophys. Res., 87(C11), 9017-9024.

Vallese, F. and J.A. Kong. 1981. Correlation function studies for snow and ice. F. Appl. Phys., 52, 4921-4925.

Zwally, H.J. 1977. Microwave emissivity and accumulation rate of polar firn. 7. Glaciol., 18(79), 195-215.

Zwally, H.J., R. A. Bindschadler, A. C. Brenner, T. V. Martin and R.H. Thomas. 1982. Surface elevation contours of Greenland and Antarctic ice sheets. $\mathcal{F}$. Geophys. Res., 88(C3), 1589-1596.

The accuracy of references in the text and in this list is the responsibility of the authors, to whom queries should be addressed. 